\title{
The Fanciest Dive
}

\author{
Jamie Lewis, ASG, USA \\ William Ritchie, James Madison University, USA \\ Fernando Pargas, James Madison University, USA \\ Mike Yankey, James Madison University, USA
}

\begin{abstract}
Clear Water Dives is an expatriate-owned Dive Resort located off the coast of Central America. This case study provides students with an opportunity to assume the role of the new resort owners who are in the process of undertaking a strategic audit of the external factors that will be influential on the resort's operations in the next five years. With an emphasis on the cultural and ecological diversity of the region, the case challenges students to consider sustainable eco-tourism factors in the SWOT analysis.
\end{abstract}

Keywords: Strategic Environment Analysis; Scuba; Tourism; Culture; International Business; Global Management

\section{INTRODUCTION}

eorge Parker firmly shook Dan Mitchell's hand for what seemed to be an eternity while the others looked on. George's wife, Sarah, shed a single tear as she embraced Alan Mitchell, Dan's brother. "Take care of our family, they'll be good to you", George said as he gingerly stepped into the boat and pulled away from he dock at Clear Water Dives Resort in Roatan, Honduras. Dan knew that he had his work cut out for him since the Parkers' global leadership skills and cross-cultural knowledge were well honed and had enabled them to conceive and develop this dive resort that was established in the early 1980s. Dan was also well aware of the strong bonds that had been forged between the Parkers and their loyal employees, respective families, and the guest divers affectionately referred to as "Water Buddies", who returned faithfully each year to the resort.

During the past week Dan, the new owner, had spent as much time with the former owner, George Parker, as George could handle. George's sale of the dive resort was the result of a combination of declining health as well as the desire to spend more time with Sarah and the grandkids. The sale of Clear Water Dives had closed two weeks before, but Dan Mitchell and his brother had flown in from South Carolina just this past weekend to attend to learning the significant details that led to the resort's success. Dan intended to work with George on all phases of the operation. Since neither he nor his brother, Alan, was certified to dive, they shared many of their memories and the many operational "challenges" that occurred over the years. Much of the reminiscing seemed to occur at down times such as meals. The Clear Water Dives staff and guests observed George sitting at the head of the table with Sarah to his left, Dan and Alan on the right, next to Tom and Jessica Metzer, the operations and assistant managers. Everyone knew they were watching the passing of a torch, a legacy long in the making.

The future held challenges for the new owners and the loyal staff at Clear Water Dives, particularly in the area of understanding the 'fit' between the business and community culture of Roatan. Dan and his brother, Alan, had vast hospitality experience from their career with hospitality and lodging in Charleston, South Carolina. Now they were expatriates at the helm of a successful business with a great reputation, but every decision they made would be scrutinized and compared to the actions of George Parker, the former owner. Literally and figuratively, the brothers were like fish out of water. Dan had limited knowledge about the business environment of Roatan as well as the "Bay Islanders" who comprised Roatan's culture. However, he believed that a SWOT analysis, with an emphasis on external factors such as political-legal, socio-cultural, technological, and economic forces, would provide the framework from which to begin evaluating their situation. With this in mind, Dan looked to Alan and said, "First things first, we must literally get our feet wet; it's time to get certified to dive." They asked David, the dive master, if he could begin the certification process with them ASAP. 


\section{Clear Water Dives}

Clear Water Dives is a small, intimate dive resort that has a stellar reputation among the global dive community. Isolated on a small island just off the coast of Roatan, one of Honduras' Bay Islands, the resort is surrounded by the world's second largest fringe reef, two wrecks, and 95\% of the marine life found in the Caribbean, including pelagic species like orca and whale sharks. The resort boasts that over 4,700 of their guests have five or more return visits. The primary competency of the organization was its ability to manage and accommodate the needs of a very diverse group of stakeholders, including the safety and expectations of the global dive community, the integration with the unique cultural dimensions of the Bay Islanders, and a focus on sustaining the island ecosystem which both delights guests and increases bookings.

Clear Water Dives is a boutique dive facility that is focused on the responsible adult diver. The limited capacity for guests has fueled the consistency of the guest experience as the resort had space for only forty divers. As a result, the guests and staff would meet and talk at mealtime, which was conveniently scheduled at regular intervals between boat departures. These buffet meals allowed guests and staff to get to know one another and rehash the encounters made during the day's previous dives while reinforcing the social networks and friendly nature of safe diving.

At Clear Water Dives, all operational efforts have been focused on maximizing divers' "bottom time." The standard dive package includes tanks and weights for unlimited beach dives and up to four boat dives a day. This operational efficiency allowed for a range of training and pleasure diving, while simultaneously maintaining a relaxed island atmosphere.

Clear Water Dive's location affords efficient dive access as it is only a short boat ride from the Clear Water Wall, Newman's Wall, and the wreck of the Prince Albert, as well as multiple dive sites accessible by boat to the east and to the west. In addition, they have a competent and experienced group of employees who work well together and are guest-focused due to their length of service and the collective and service-oriented nature of the culture on the island.

In addition to the 32 guest rooms that are built at the water's edge and whose windward location enjoys a constant breeze, they have access to five beach properties adjacent to the main facility at the Playa San Miguel rentals which can be used for guest overflow. Since they are on a cay 200 yards from the mainland, which is only accessible by a launch, they have a natural barrier that protects guests from some of the security issues that are often faced by expatriates on Roatan.

Clear Water Dives provides round-the-clock access to diving through the use of four custom-built 50-foot dive boats with storage for 150 dive tanks. The professionalism and teamwork exhibited by their employees is reinforced by an internal culture of respect and family-like atmosphere, sharing meals with them, and allowing them flexible scheduling, including free lodging for week-on/week-off workers. A recommended group tip from guests at the end of their stay, instead of daily individual tipping, also reinforces the team dynamics.

\section{Local Community}

The island location provides some challenges to Clear Water Dives. The Honduran government has an inability to provide basic infrastructure like water, consistent electricity, and enforcement of laws to protect the delicate ecosystem. In addition, the food supply is sometimes at risk since the resort must depend on foods produced and processed without the inspection and regulations they are accustomed to in the developed world. There had been an incident in 2003 where some contaminated cheese created a food poisoning outbreak and the fallout resonated on message boards throughout the Internet. New guest bookings dropped while repeat guests bookings felt little impact. The resort recovered by addressing the issue head-on and reimbursing guests while simultaneously offering a complimentary week to return. There have also been complaints about the No-Seeums (biting sand flies) discouraging children from being brought to the resort. The No-Seeums are a natural phenomenon that only occurs on the narrow strip of beach and only at dusk and dawn. The resort recommends that guests use a strong insect repellent to alleviate this nuisance. Other guests have requested that they increase the numbers of air-conditioned rooms and to add a pool. 


\section{HISTORY}

In 1980, after becoming fed up with the mining business in Ohio and needing a break, George and Sarah Parker sailed their Endeavor 33-foot - "Rocky Road" - to Port Royal, Roatan, in the Bay Islands of Honduras. Roatan was a little known piece of paradise back then, so George and Sarah relaxed and the island seemed to let their Ohio woes fade away. The couple made several friends and they eventually fell in love with the island and its people. George and Sarah began to consider the idea of just staying for good, but in order to do that, the couple needed to create a source of income. George decided that a live-aboard dive boat would enable the two of them to explore the reefs surrounding Roatan and generate a source of income as well.

Along with their good friends, John and Kathy Adler, George and Sarah came up with the idea to turn a 60foot hulking boat into a live-aboard dive vessel. The first priority became to find an air compressor and someone to fix and maintain it. Through word-of-mouth recommendation, they found Bud Noble, the island authority on compressors. Bud became a key ingredient to what began and drove the evolution of Clear Water Dives Resort. Bud has been a long-time friend and business associate of George's and their friends, John and Kathy, have also supported the growth of the business over the years. George and Sarah readily admit that none of the successes of the business would have been possible without the hard work, determination, and friendship of these five people.

George, John, Bud, Sarah, and Kathy all focused their energies to turning this less-than-ideal boat into a functioning live-aboard vessel. The "Wayfarer" ran her maiden voyage in 1981, loaded with a group of intrepid souls (many of whom are still long-time Clear Water Dives guests).

A student of continuous improvement, George sat down and started evaluating the task environment. In order to establish the dive business, the boat would need a dock. A strategy and functional objective was set to target and locate a 'suitable' piece of waterfront to build the boat dock. According to Sarah, he settled on "the most desolate piece of waterfront property anyone had ever seen" and contacted the owner in Germany who had inherited it. Word soon spread throughout the island that some crazy gringo had bought the useless piece of swamp. The original island property consisted of one barely habitable concrete building, a second concrete shell, and a large wooden bodega or storehouse.

Creating the appropriate dock service for the 'Wayfarer' would take a significant investment of ingenuity and manpower. The dock service would also need a few supplies, which were fairly scarce considering the resources available in the Bay Islands of Honduras. It made sense to borrow things off the boat. In time, the decision was made to move the compressor from the boat to the dock. This necessitated a change in the internal environment of the business and a shift in mission, strategy, and functional goals.

With the compressor now on the dock and the guests still on the boat, living quarters were very crowded. Consequently, a decision was made to build some rooms and give divers a place to stay, so the two land-based concrete structures were given their first of many makeovers. As a result, the infrastructure of the 'Wayfarer' wasn't needed for guest-quarters, so it was placed on pilings to become staff housing for the ladies.

The resort currently has six more buildings which provide guest rooms, in addition to the clubhouse and dockside building which houses the compressor, a PADI five-star dive center, and dive gear rooms adjacent to the assigned dive boat. The dockside building has assigned storage that is matched with specific color-coded dive boat that is specifically assigned to the guest diver and/or their dive group upon arrival. Generally, guests dive with the same dive master throughout their stay. Divers let the dive master know whether or not they are diving by placing a marker on their storage lockers which are located directly behind their assigned boat. The only responsibility the diver has is to be on the boat by departure time as the dive master loads the equipment. Departures and brief descriptions of the dive locations are posted along with the daily dive destinations and the divers' boat assignments.

\section{The Bay Islands Of Honduras}

Located about 40 miles off the northern coast of Honduras, the Bay Islands group consists of three main Islands (Roatán, Guanaja, and Utila), three smaller islands (Barbareta, Morat, and Helene), and 65 smaller cays. 
Between these islands and the mainland are the Cayos Cochinos. The Bay Islands are the above-water expression of the Bonacca Ridge, an extension of the mainland Sierra de Omoa mountain range that disappears into the Caribbean Sea near Puerto Cortes on the Honduran mainland.

The Bonacca Ridge forms the edge of the Honduran continental shelf in the Caribbean. As a result, the northern ocean-facing sides of the three main islands, with their shallow waters, extend just beyond the shore before dropping off to sheer underwater cliffs and the deep waters of the Caribbean. In contrast, the south side of the island, which faces the Honduran mainland, is much shallower. Surrounding Roatan is a fringing reef on the southern shore which is often confused with a barrier reef, the difference being the relative proximity to the shore line. A barrier reef creates a large lagoon area which surrounds the island, while a fringe reef begins just offshore.

\section{Roatan's Cultural Roots}

While the Bay Islands of Honduras might not be the most well-known or marketed destination in the Caribbean, there might be a general tendency to see small island communities as traditionally remote and isolated. Yet this view is historically erroneous and, in fact, the history of the islands of the Caribbean, as well as the islands of the Pacific and Indian Oceans, testifies to the great cultural interaction and mixing that small islands have to offer. Indeed, it may be much more appropriate to understand islands as cultural crossroads. Small islands, far from being "remote and isolated", have, in fact, always served as great "crossroads" for human cultural interaction.

During the Maya reign in Central America (between the 4th and 10th centuries), the Paya Indians populated the Bay Islands. The Payas were a smaller and less sophisticated group than the Mayans of Central America and were related to the Pech Indians who resided near Trujillo on the mainland. Their civilization was characterized by distinctive, simpler, and less ornate housing and tools than the Mayans. Payan artifacts (pottery, jade, and shells) are often found in island burial and ceremonial sites and are referred to by the locals as "yaba ding dings." Most of the pre-Columbian sites have been thoroughly sacked with no regard for their archeological value. Artifacts have been removed without any record of their origin or heritage patterns. As a result, little is known about the Payan culture and most theories are speculative at best.

Prevailing theories are that the island Indians mined jade which they took in small boats to the mainland to trade for tools and other items. Most agree that food resources were plentiful, even until the $19^{\text {th }}$ century. The islands provided an abundant variety of foodstuffs such as yuca, fish, corn, turtles, iguanas, agouti/watusa (island "rabbits"), native fruits, land crabs, and deer.

During the 13th and 14th centuries, Europeans discovered these islands. For almost 200 years, the Spanish conquistadores and the British pirates battled for control of these islands, ignoring the indigenous Indians' stake in the land resources. During this period, the islands were used for food and wood supplies, safe harbor, and slave trading. Remains of old British forts and towns named after famous pirates continue to be their legacy. The historic record states that Welsh privateer, Henry Morgan, operated out of Port Royal and the town of Coxen Hole was named after John Coxen, another privateer. While these buccaneers were on the island, most of the pirates' activities were centered on hunting, fishing, or fixing boats, so often only temporary shelters were built. The few structures which remain were built as defensive fortifications and are ironically the location of present day gated communities and luxury homes.

The earliest immigrant settlement on Roatan is a result of some 4,000 natives from the island of St. Vincent in the eastern Caribbean who were unceremoniously dumped on the deserted island on April 12, 1797. These are the Garifuna who currently populate much of the Bay Islands, still maintaining their own cultural identity and language. Having originally been left near Port Royal on the south side of Roatan Island, many of the Garifuna moved on to the mainland shortly thereafter. However, those who remained on Roatan found the calmer waters inside the reef and the abundance of coconut palms (Cocos nucifera) that are useful for building shelter and for food resources. Punta Gorda on Roatán is one of many villages where native Garifuna still build their homes from traditional materials such as mud brick, sugar cane, and thatched coconut palm. 
The Garifuna were followed by a wave of immigrants in the 1830s that left the Cayman Islands after slavery was abolished there. Although isolated settlers lived on the islands when the Cayman Islanders arrived, these newcomers laid the foundations for the present day towns of Coxen Hole and the West End, as well as the smaller hamlets tucked in the bights on the eastern end of Roatan.

During the early part of the $19^{\text {th }}$ century, the British government saw the Bay Islands and Roatan as a useful geopolitical tool in its struggle with the United States for control over Central America. As a result, the British claimed ownership of Roatan and the other Bay Islands. Although the British ceded the ownership and recognized Honduran sovereignty in 1859 , lack of comprehensive governmental oversight continued for many years, owing to the fact that many islanders believed they were part of the British Empire well into the early part of the $20^{\text {th }}$ century.

\section{Current Environment}

Roatan continues to evolve with an annual population increase of about $9 \%$ per year and changes are driven by the ever-increasing dependence on a growing cash economy, the influx of inexpensive labor from the mainland, and the ever-increasing influence of western tourism and retirees who choose Roatan as their piece of paradise. The population pressure on this small island is exacerbated by the gradual decline of the banana industry on the mainland, world-class diving, and opportunistic real estate speculation.

In 1990, 15,000 tourists came to Roatan; by 1996, that number exploded to 60,000. Hurricane Mitch temporarily destroyed much of the island forests, adversely impacting its attraction as a tourist destination. Additionally, deforestation as the result of the traditional method of swidden (slash-and-burn) horticulture continues to threaten the trees and precious topsoil. The silt that erodes into the surrounding reef threatens to choke the coral which depends on photosynthesis and the symbiotic relationship with algae, but some blind opportunists toss caution to the wind and insist on grazing cattle in addition to the slash-and-burn methods of horticulture. Furthermore, the once pristine beaches and verdant hillsides are now sites for homes, restaurants, resorts, and other developments. Replacing a local labor force that has gone to work on oil derricks and cruise ships in search of more money, the Ladinos and Moskito Indian immigrants from the mainland have made the shrimp industry a vehicle for their own prosperity. Consequently, over-fishing has led to bans (Vedas) during certain months of the years, but their usefulness is limited by a lack of both oversight and regulatory enforcement. The processing plants on Roatan purchase whatever comes their way regardless of season and they turn a blind eye toward the Vedas.

The expatriate community and wealthy landowners on Roatan continue to yearn for the days and the ways of the past. The working class looks to cruise ship traffic as their meal ticket. The island is visited by several cruise lines, such as Princess, Royal Caribbean, and Norwegian Cruise Lines. A new cruise ship stop named Mahogany Bay opened up recently outside of French Harbor. Cruises also port in Coxen Hole.

The working poor view it as an opportunity; however, residents who don't need the monetary support from tourists desire that the island returns to traditional lifestyles. The beauty of the island is only surpassed by the warmth and attractiveness of its people. It seems that those who have the least, in terms of material possessions, are willing to share what they little they have. They offer their time and their families, which begs the question, "Who is more wealthy - those who have most or those who need least?"

As tourism and development continues unabated, fresh water supplies are being strained and the need for a modern infrastructure is becoming ever apparent. RECO (Roatán Electric Cooperative) provides adequate electricity, but no sewage or water treatment plants presently exist. Although land lines are difficult or impossible to obtain in many places, cell phone service is widespread and cable television and wireless internet service are also widely available.

Armed robberies targeting the wealthy are not uncommon. Although details of such events are anecdotal, it does underpin a real fear in the colonialist and expatriate community. Some have reported that robberies are carried out with military precision (e.g., dogs are poisoned, locks are jammed, and teams of bandits armed with automatic weapons target a specific property). The local sense is "if you have so much that you can't keep track of your property or secure it, it deserves to be stolen". The perception of the locals is that the wealthy reside in their fortified 
castles on mountaintops, while the peasant working class toils beneath them, working the land and the sea for sustenance.

The Inter-American Developmental Bank and the Honduran government are, after several years of delay, implementing a multi-million dollar loan program aimed at improving infrastructure in the Bay Islands. Another local organizational effort is the Bay Islands Conservation Association (B.I.C.A) which focuses on preserving the ecosystem through education. These proposed projects aim to alleviate some of the harsh effects of tourism-related development on the marine and terrestrial ecosystems and on island culture. The main goals of these projects are to improve the potable water supply and waste disposal, preserve endangered species, and implement strict regulations on construction and road building. These efforts will safeguard against erosion and reduce the loss of scarce topsoil and contaminants in hopes of protecting the reef. However, the prevailing thought is that because of the underlying problem of poor governmental oversight, the problems will exacerbate and the Honduran debt load will just increase.

\section{Roatan And The Global Tourism Market}

Roatan and the other Bay Islands are a relatively isolated dive destination when compared to the Islands of the Eastern Caribbean or the more well-known destinations of the Yucatan Peninsula, such as Cozumel or Belize. Presently, the islands are only accessible directly by air via flights originating in Miami, New York, Houston, and San Pedro Sula, Honduras. This limited access has allowed the island to hold on to its traditional cultural identity longer than other island destinations. However, cruise ship traffic has significantly increased in recent times, encroaching on Roatan's resources and infrastructure. However, this has primarily impacted the west end of the Island, leaving its mark on areas like Coxen Hole, Sandy Bay, and the 'trendy' West End. On the more rustic east end of Roatan, Clear Water Dives compromises some of its commercial visibility for guest loyalty in contrast to larger commercial operations like Martha's Key Resort. Martha's Key is privately owned by the Jones family who is an established local political entity with influence rooted in land holdings and local government.

A visible competitor, Martha's Key Resort, is also a PADI five-star resort; in addition, it is the home of the Bay Islands Conservation Association (BICA), as well as a dolphin research center, and has a capacity to handle over 100 guests at one time. The slightly upscale Martha's Key Resort also offers convenient access to the more western-style amenities of the West End like international-style cafes, souvenir shops, and tourist attractions like parasailing, boat tours, horseback riding, and the American-style restaurants and bars. As a result of this global influence, the West End of Roatan has also begun to experience a real estate boom as a destination for expatriate retirees who find they can purchase a piece of paradise for much less than in the United States, Mexico, Costa Rica, or the eastern Caribbean.

Roughly 20 miles east of the West End is Coxen Hole, which is the traditional center of commerce for Roatan. In this location, the island government, the cruise ships, and locals converge in a colorful mix of language, food, and social behaviors. Coxen Hole is also the gateway to mainland Honduras via a ferry to La Cieba. On the main streets in Coxen Hole, one encounters extreme poverty, school children, missionary groups, police with automatic weapons, and street merchants which all blend in cacophony of sights, sounds, and aromas. There seems to be ongoing attempts to enhance the thoroughfares and sewage systems throughout town, but the projects always seem to go over budget, over established deadlines, and are unable to keep up with the unrelenting growth. The concept of time here is polychronic in contrast to the monochronic paradigm of time in the United States. This is often referred to as "Island Time".

On the extreme eastern end of Roatan, ten miles past Punta Gorda, another more isolated dive establishment is found at Paya Bay, which is also a resort with an impressive vantage point overlooking the Caribbean and private beaches which face the northern barrier reef that surrounds Roatan. Paya Bay is owneroperated by the McNabb family who are descendants of the some of the seafaring British Colonials that occupied the islands during the late $18^{\text {th }}$ century.

At Paya Bay, diving is one of a number of activities offered, which include boat trips to neighboring Cays and day trips that consist of picnics with barbeques of island fare provided by a local chef. At Paya Bay, solitude and 
the remote island beauty is the centerpiece of the business and the access to diving is reduced to an amenity. Afternoons are spent on a hammock or in the open air dining room which offers live entertainment of black throated hummingbirds that hover around feeders while music from reggae to meringue is caught in the constant trade wind breezes.

\section{Scuba Diving: A Convergence Of Technology, Ecology, And Culture}

The historic precursor to scuba diving is skin diving which has roots that can be traced back to the ancient Greeks and Japanese who dove for bivalve mollusks and sponges. At that time, "free diving", which is diving unencumbered by equipment, necessitated the ability to hold a breath of air and penetrate a water column until a build-up of carbon dioxide placed a time and depth limit on the diver. Modern aquaculture has displaced many of the traditional Japanese pearl divers, but some persist in free diving to this day.

Recreational skin diving or snorkeling requires the diver to don three basic pieces of equipment- an airtight face mask enclosing an air bubble which allows for clear vision, a snorkel for breathing within a foot of the surface, and fins for propulsion which mimics the webbed feet of aquatic animals. The snorkeling technique employs a ' $\mathrm{j}$ shaped' snorkel tube and mouthpiece for breathing on the surface, while the a skin divers must hold his breath and quickly propel himself perpendicular to the surface toward the sea bottom to achieve any significant depth in the water column.

In 1943, a member of the French navy made the most significant technological breakthrough that allowed humans to penetrate and explore the previously hostile aquatic environment. It was then that Jacques-Yves Cousteau and Emil Gagnan developed the aqualung for SCUBA diving. SCUBA is the acronym for Self Contained Underwater Breathing Apparatus. While the original function of SCUBA was for clandestine insertion of military personnel and for placement of underwater explosives, soon this technology opened up a new world of exploration for recreational divers. Even Cousteau himself promoted a global awareness of the marine ecosystem through underwater photography, bringing back images of a colorful and a diverse marine environment never before seen. Now divers were able to extend the temporal and spatial limits of skin diving by carrying pressurized bottles of air on their backs. Rubberized and neoprene wetsuits were developed to prevent hypothermia as the human body's core temperature is conducted five times as fast in water than in air.

The technological breakthrough of the aqualung, or SCUBA equipment, fomented the development of dive science or the intertwining of the physics of human biological systems and the emerging technologies to increase the depth and bottom time of the military, commercial, and recreational diver. There are three key pieces of diving equipment that are constantly under development. First, the regulator, which is a key component that is basically a mouthpiece and valve that replaces the snorkel as the breathing apparatus and interface of the life support system. The regulator depends on a one-way valve that responds to the negative pressure of inhalation and automatically adjusts to the ambient water pressure protecting the alveoli in the lungs from significant fluctuations in pressure.

Second, the ability to alter and remix the breathing gases which are pressurized in the tank to reduce the threat of the bends, nitrogen narcosis, and oxygen toxicity at depth. For the recreational diver, a Nitrox mix increases the percentage of oxygen from $21 \%$ to a range of $32 \%$ to $40 \%$, thus reducing the percentage of nitrogen. Military and commercial divers employ additional gases, like Helium and Argon, for technical dives below 100 meters (32 8ft.). Recreational dive organizations strongly recommend that divers never go beyond 40 meters (130 $\mathrm{ft}$.) to avoid the life threatening implications of convulsions, blackouts, or nitrogen narcosis (rapture of the deep).

Finally, in addition to the ability to measure gas, time, location, and depth using a pressure gauge, watch, compass, and depth gauge (or dive computer), the buoyancy compensator (BCD) and weight belt are critical pieces of equipment for the diver. The BCD and weights allow the diver to hover weightlessly in the water. Lately, the buoyancy compensator has been integrated with the weights to streamline the diver profile underwater. A secondary air regulator, secondary air source, and a dive knife are also recommended, as is a designated buddy.

Certification organizations, like PADI (Professional Associations of Diving Instructors) and NAUI (National Association of Underwater Instructors), create a common training focus on dive safety and ecological 
literacy. These shared values, which permeate dive culture, are enforced by the requirement of certification for gas refills and prohibition of technical diving, like caves or wreck penetration without the proper levels of education and certification. In addition, the concept of redundant life support systems - from additional air supply to always diving with a buddy - creates a unique culture that creates a shared respect for the inherent risks of scuba diving while strengthening the human bonds that we often take for granted on the surface.

In addition, the dive community is enjoying the natural environment of coral reefs and other marine life in greater numbers through these advances in technology and dive science. Unfortunately, the unfettered uses of technology using fossil fuels and environmental irresponsibility, like lack of soil conservation and pollution, have begun to degrade the integrity of the coral reefs, threatening the interdependent marine life, and ultimately the food chain - a system on which all life forms depend.

\section{Scuba: The Tourism Market}

Cline Group (www.williamcline.com), a scuba industry consultancy, valued the U.S. dive industry at $\$ 3.2$ billion in $2010,72 \%$ of which was travel-generated revenue. Growth in this segment ranged from three to five percent in 2007, while spending in the segment was relatively flat for the period 2008-2010. There are three million certified scuba divers in the United States, according to the Sporting Goods Manufacturers Association (www.sgma.com) - six times the number in the early 1980s. Approximately 35\% of U.S. divers are women. According to the Gallup Organization (www.gallup.com) in a poll sponsored by the Diving Equipment and Marketing Association (www.deman.org), $8 \%$ of adults are active scuba divers. Average household income is $\$ 61,300$ for this group. The fastest-growing part of the scuba travel industry is "live-aboards" - 100-foot luxury yachts that carry 10 to 20 divers form one isolated dive location to the next. These unique adventures typically cost about $\$ 1,700$ per person per week. Popular among divers are aquatic encounters with large sea life, such as swimming with and photographing giant manta rays, dolphins, stingrays, and hammerhead sharks.

While the broader tourism market has been adversely affected by the worldwide economic decline from 2008 to 2012, diving tourism, which appeals to higher income brackets, has experienced a lower rate of decline. However, recent hurricanes and the variability in the length of hurricane season have had a negative impact on the Caribbean dive industry as a whole. In response, the government of Honduras continues to look for ways to encourage tourism projects, including tax incentives for projects with favorable results. The government is also working on projects to enhance security to ensure the safety of foreign tourists.

\section{CONCLUSION}

Dan's challenge is to assess Clear Water Dives' current situation in light of the many external influences on this organization. A SWOT analysis is an appropriate framework to organize the information with an emphasis on external factors that pose opportunities and threats to Clear Water Dives. Clarifying these factors will provide Dan with important information as he plans for the future of the business.

\section{AUTHOR INFORMATION}

James F. Lewis, M.B.A. works with ASG in Naples, Florida. As a SCUBA and Travel Enthusiast, James is interested in how organizations leverage cultural dimensions to achieve a sustainable competitive advantage as well as organizational development and information technology systems that best support the organizational structure.

William (Bill) J. Ritchie, Ph.D. is Associate Professor of Management at James Madison University where he teaches strategic management and quality management. Bill's research centers on strategic implications of adoption of standards and nonprofit performance measurement. His research appears in journals such as Nonprofit Management \& Leadership, Strategic Management Journal, and Management Decision. E-mail: ritchiwj@jmu.edu (Corresponding author)

Fernando Pargas, M.B.A., was born in Uruguay and has established and managed businesses throughout the world. He served as Vice President of International for Time Warner Inc.'s Time Life International and is the author of 
Stopping Big Business and Politics from Bleeding America-An Agenda for the New Generation, as well as Ending the Male Leadership Myth: How Women Can Save Us From Destroying Ourselves He teaches Management at James Madison University. Fernando is also an Instructor for the Center for International Stabilization and Recovery in the U.S., Amman, Jordan, Geneva, Switzerland, and Lima, Peru.

Mike Yankey, M.B.A., has been on the faculty at James Madison University since 2000. He teaches in the Management department, and has taught Principles of Management, Interpersonal Skills and Strategic Management. He has a strong background in retail management, having worked for several years in that field. He has co-authored several well received journal articles with his colleagues. In addition to teaching on the main campus, he has also taught for JMU at the University of Antwerp in Belgium. In addition to teaching, his other professional interests center on student advising and first-year student involvement. 
NOTES 